\title{
Paisaje e identidad. El Río Papaloapan, elemento funcional Y SIMBÓLICO DE LOS PAISAJES DEL SOTAVENTO
}

\author{
Landscape and identity. Papaloapan river, functional and symbolic element of the Sotavento's landscapes \\ Virginie Thiébaut
}

Resumen: Los paisajes son realidades tangibles pero también elementos identitarios que participan en la conformación de los grupos sociales. En la cuenca baja del Papaloapan, el río ha tenido una gran importancia a lo largo de los siglos. Además de vía de comunicación esencial, proveedor de alimentos y fuente de fertilización de las tierras, estaba también fuertemente relacionado con las creencias religiosas. Durante el siglo XX perdió casi todas estas funciones porque las vías de comunicación terrestres sustituyeron al río y la contaminación de las aguas y el azolve provocaron la disminución de la actividad pesquera. En este trabajo estudiaremos los paisajes fluviales del Papaloapan en toda su amplitud para entender si los cambios funcionales han llevado a la modificación de la percepción del río y del sentimiento de identidad por parte de los habitantes ribereños.

Palabras clave: paisaje, ríos, identidad, evolución, vías de comunicación fluvial.

Abstract: Landscapes are tangible realities, but they're also elements of identification that participate in the conformation of social groups. At the lower basin of the Papaloapan, the river had great importance along the centuries. As an essential communication via, provider of foods and source for the land fertilization, it also was strongly related to the religious beliefs. During the 20th century, it lost almost all of these functions: mean while the land communication routes replaced the river, water contamination and sedimentation brought the decrease on the fishing activities. Trough this article, we will review the fluvial landscapes of the Papaloapan river in its whole scale to understand whether the functional changes had drove to the modification of the river's perception and the sentiment of identification by the river dwellers.

Keywords: landscape, river, identity, evolution, communication routes, waterways.

\footnotetext{
Virginie Thiébaut, doctora en Geografía por la Universidad de Nancy 2, Francia, investigadora en el Centro de Estudios de Geografía Humana de El Colegio de Michoacán, correo electrónico: virginiathiebaut@yahoo.fr.
}

Enviado a dictamen: 22 de junio de 2013. Aprobación: 27 de junio de 2013.

Revisiones: 1. 
$\mathrm{P}$ ara los investigadores en ciencias sociales, y especialmente para los geógrafos, el territorio es un elemento importante de la conformación identitaria de los grupos sociales. Según Di Méo, al mismo tiempo que la identidad legitima un grupo en el espacio, el proceso identitario utiliza el territorio como uno de los cimientos de la construcción social. Los grupos sociales se identifican con elementos territoriales específicos como objetos, lugares y sobre todo paisajes (Di Méo, 2002, 2004). Nogué, por su parte, considera que "los paisajes evocan un marcado sentido de pertenencia a una colectividad determinada, a la que le otorgan un signo de identidad" (2006: 136). Según él, los paisajes no son solamente una realidad física, sino además una construcción social cargada de valores culturales y de significados, algunos de cuyos elementos se vuelven simbólicos. Es importante señalar también que la configuración de estos paisajes culturales, elementos de la identidad de los grupos sociales, evoluciona de manera constante, de tal forma que algunos de sus componentes desaparecen, otros se transforman y surgen nuevos. En este trabajo queremos correlacionar la transformación histórica de los paisajes físicos con la percepción que se tiene de ellos para evaluar si las modificaciones funcionales llevan necesariamente a la transformación del sentimiento identitario.

Para tal fin, nos pareció esencial estudiar la génesis de los paisajes actuales, puesto que solamente mediante la reconstrucción de los paisajes del pasado podremos entender la conformación actual del territorio. Los paisajes fluviales nos parecieron especialmente interesantes por ser móviles y por representar realidades variadas, tanto temporal como espacialmente, ya que siguen un eje central a lo largo de varias decenas o centenas de kilómetros. ${ }^{1}$ Además, son pocos los estudios de geografía cultural que se enfocan en ellos. Entre los más recientes destaca el de Pizarro sobre el río Amazonas (2009), donde el autor aborda aspectos históricos y actuales, espacios vividos y usos del río, así como los imaginarios y percepciones a través de los discursos sobre el río - las voces del río- - El estudio de Silvestri acerca del río Riachuelo en Argentina (2012) se refiere a los aspectos estéticos, históricos y sobre todo funcionales, especialmente en sus capítulos dedicados a las actividades industriales y al puerto y los canales.

Cercano a estos trabajos, nuestro estudio sobre la cuenca baja del Papaloapan, entre la desembocadura del río en el Golfo de México y la localidad de Tuxtepec, situada al pie de la sierra de Oaxaca, tiene como objetivo evaluar los papeles funcional y simbólico de la corriente de agua y su importancia en los paisajes (ver mapa 1). En primer lugar, se determinarán las distintas funciones que tuvo el río en el pasado para las comunidades de la región como vía de comunicación y eje de los asentamientos humanos y de las actividades productivas. En segundo lugar, se investigarán los cambios y las dinámicas territoriales del siglo XX, especialmente los nuevos medios de comunicación y el desarrollo de la actividad industrial, así como su impacto para las comunidades con la pérdida de importancia del papel funcional del río. Finalmente, evaluaremos si estos cambios provocaron la modificación del sentimiento de identificación de los grupos sociales con el río Papaloapan y la desaparición de su papel simbólico. Este trabajo pretende aportar nuevos elementos para entender el proceso de apropiación social y cultural de los espacios fluviales por sus poblaciones e intentar precisar la relación entre identidad y paisaje.

Para complementar y enriquecer la información bibliográfica que encontramos, principalmente histórica, efectuamos varias estancias de trabajo de campo en la cuenca baja del Papaloapan durante los años 2012 y 2013, con el objetivo de observar los paisajes y realizar entrevistas a los habitantes de los pueblos ribereños. En una primera etapa, intentamos reconstruir los paisajes del siglo XX y su evolución a fin de entender las relaciones que existían y siguen existiendo entre los habitantes y el río. Para obtener esta información, nos acercamos principalmente a gente de edad avanzada que tuvo, y a veces sigue teniendo, cierto acercamiento con el río. Con este fin, en mayo de 2012 realizamos 25 entrevistas en 11 localidades distintas durante dos estancias de seis días cada una. Para referirnos al otro aspecto específico de la investigación - conocer el río como elemento identitario y entender su importancia simbólica- 
organizamos una segunda etapa de trabajo de campo en marzo y abril del año siguiente - dos estancias de seis días-, durante la cual aplicamos 63 entrevistas en cuatro de estos pueblos situados en distintos puntos del río: Tlacotalpan, Amatitlán, Chacaltianguis y Otatitlán (ver mapa 1). En este caso se buscó cierta representatividad de la población, por lo cual nos acercamos a personas de distintos género, edad y categoría social (ver tabla 1). Los objetivos que se reflejan en la guía de entrevista consistían en definir la importancia que tuvo y tiene el río Papaloapan en la identidad de los habitantes y si su percepción de la corriente de agua ha evolucionado con el tiempo. Asimismo, tomamos contacto con los directores de escuelas primarias en cada uno de los pueblos y les solicitamos ocupar durante media hora dos salones de clase para que los alumnos pudieran realizar un dibujo de su pueblo. Los niños de entre siete y diez años recibieron como única instrucción la de representar su pueblo; de esta manera, los 78 dibujos obtenidos nos permitieron evaluar la importancia que tiene el río para ellos al observar la representación que se hacen de su territorio. En este caso, el objetivo final era el mismo que con los adultos, pero no utilizando preguntas, sino dibujos. Queríamos saber además si la percepción de los niños variaba de un pueblo a otro y si coincidía con la de los adultos.

Gracias a estas distintas técnicas, recolectamos información diversificada sobre los paisajes fluviales, como realidad física y como elemento de identidad, tanto en el pasado como en el presente.

\section{El río Papaloapan en la época colonial: eje de vida, comunicación y creencia}

La colonización española provocó cambios drásticos en la cuenca baja del río Papaloapan al igual que en gran parte de la Nueva España. La estructura de la población se modificó por las epidemias y por el consecuente desplome de la población indígena. A partir de finales del siglo XVI, la población sobreviviente de nahuas y popolucas se mezcló gradualmente con españoles, y sobre todo con esclavos negros, para dar lugar al incremento en la población de mulatos y pardos. A pesar del crecimiento de esta población, el derrumbe demográfico continuó hasta el siglo XVIII, de tal manera que provocó el despoblamiento de zonas enteras de la cuenca (García de León, 2011: 154).

Aprovechando ese vacío y la desaparición de numerosas localidades indígenas, se crearon en los siglos XVII y XVIII grandes haciendas y mayorazgos dedicados a la ganadería extensiva como resultado de la concentración de estancias formadas durante el siglo XVI (Velasco, 2004: 60). El ganado conquistó las inmensas extensiones abandonadas por los humanos y la actividad ganadera, poco exigente en mano de obra, se volvió predominante en toda la cuenca. Como la agricultura era poco compatible con los grandes hatos de ganado que se crearon y vagaban libremente — cimarronaje-, los cultivos tradicionales —algodón, maíz y cacao-, practicados al inicio de la época colonial por los indios para pagar el tributo al encomendero, se quedaron reducidos a la cercanía de las localidades y a tierras periféricas a las haciendas, en las cuales se asentaron progresivamente poblaciones afromestizas (García de León, 2011: 625-626).

Los cambios de actividades y demográficos provocaron modificaciones en la organización espacial, aunque hubo también ciertas permanencias. En los siglos XVII y XVIII desaparecieron numerosas localidades, pueblos sujetos pero también cabeceras, como Puctla y Guaspaltepec. Los otros asentamientos perdieron gran parte de su población, pero los intentos de reagrupar a los vecinos en congregaciones con el fin de controlar, evangelizar y asumirlos como tributarios no tuvieron siempre éxito, al igual que en otras partes de la Nueva España. Hubo una fuerte resistencia por parte de los vecinos a permanecer en puntos estratégicos, como la orilla del río Papaloapan o la confluencia con un afluente. ${ }^{2}$ Por ejemplo, los asentamientos prehispánicos de Tlacotalpan, Cosamaloapan, Chacaltianguis, Tlacojalpan y Otatitlán conservaron su ubicación (García de León, 2011: 138-167).

En los argumentos presentados por los habitantes para quedarse en el mismo lugar, el acceso al río y el contacto con él fueron mencionados de manera 
recurrente. Las principales actividades practicadas por la población estaban vinculadas a la corriente de agua. Era el caso de la pesca, labor tradicional de los indígenas y posteriormente de los mulatos y negros y de los españoles, como resultado de la atribución de caballerías de tierras para fundar pesquerías a partir de mediados del siglo XVI (Velasco, 2003: 127). Producto de consumo básico en las comunidades, el pescado secado y salado se mandaba también a las grandes ciudades del Altiplano y a Oaxaca. Para la ganadería, el acceso a las tierras ribereñas, temporalmente inundadas y abonadas por los aluviones, era también esencial. Estas tierras fueron causa de pleito entre los propietarios de los latifundios ganaderos -interesados en aprovechar los pastos abundantes - y las comunidades indígenas, en especial los pescadores (Aguirre, 2008: 283).

Por otra parte, el río Papaloapan tenía un papel estratégico como vía de comunicación y era importante poder acceder a él fácilmente. Formaba parte de la extensa red de vías acuáticas complementada por caminos de herradura y utilizada por los pobladores para desplazarse y transportar mercancías entre las tierras de la sierra de Oaxaca y la costa (ver mapa 2). Después de pasar por Tlacotalpan y Alvarado, los productos - algodón, textiles, cera, miel, aguardiente, pescado, cueros, frutas, maderas preciosas - llegaban al puerto de Veracruz para emprender el viaje hacia destinos de ultramar u otros puntos del Caribe navegación de cabotaje - o pasaban por el río Blanco y caminos de arrieros para alcanzar el altiplano vía Orizaba (García de León, 2011: 139, 843-862). En el sentido contrario, las mercancías obtenidas de ultramar o de otras regiones - vino, aceite o sal de Campeche- llegaban al puerto de Veracruz, luego a Alvarado y Tlacotalpan, para penetrar después hacia las localidades ribereñas y tierra adentro por los principales afluentes del Papaloapan y las vías terrestres. Las grandes bodegas situadas en distintos puntos de la orilla de los ríos permitían acopiar las mercancías y una gran variedad de embarcaciones canoas, bongos, lanchas ancheteras y navíos - recorría las vías fluviales todo el año. Hay que notar que el río, vía de comunicación esencial, podía ser también un obstáculo para el transporte, en especial para el ganado en pie que subía a las grandes ciudades del altiplano, donde había una fuerte demanda; éste se transportaba únicamente en los meses secos, cuando bajaba el caudal y podía vadearse o transitar por los pasos.

Además de estos aspectos funcionales, sabemos que el río estuvo vinculado en la época colonial con la aparición y veneración de imágenes religiosas. Al inicio de la época colonial, los evangelizadores franciscanos entronizaron santos patronos, los cuales fueron progresivamente sustituidos por otras imágenes más vinculadas al río y relacionadas con los dioses del agua que anteriormente veneraban las poblaciones prehispánicas. Algunos ejemplos son los siguientes: la celebración de la virgen de la Candelaria en Tlacotalpan coincide con la de la diosa prehispánica de las aguas, Chalchiuhtlicue; según la tradición, la virgen de la Soledad de Cosamaloapan fue hallada por los indios en el río después de una inundación, y el Cristo negro llegó a Otatitlán desde Alvarado por vía fluvial (Córdoba, 1998). El río era ya entonces un elemento fundamental en la construcción identitaria y religiosa de los pobladores.

Para concluir esta primera parte, puede decirse que el río Papaloapan jugó un papel central en la organización territorial de la época colonial porque era el eje de los asentamientos humanos, la principal vía de comunicación y un proveedor de alimentos; asimismo, regía las actividades de subsistencia, los viajes de las personas y de las mercancías, y también las creencias religiosas. Hay que resaltar además que la población consideraba sus crecidas como una ventaja, ${ }^{3}$ en especial por la fertilización de las tierras que ocasionaba (Velasco, 2011), como lo certifican los pleitos por los terrenos bajos temporalmente anegados, los cuales se valoraban por la calidad de los pastos y la actividad pesquera que en ellos se daba. En cuanto al transporte, éste se hacía por vía terrestre o fluvial según la temporada fuera de lluvia o de secas, el ganado se trasladaba entre las tierras bajas y altas, y los ciclos de cultivo se adecuaban a las crecientes en una dinámica permanente de adaptación de las poblaciones a la movilidad del río. 
Reorganización territorial y pérdida de la importancia funcional del río en los siglos XIX y XX

\section{El porfiriato y el ferrocarril}

Durante el siglo diecinueve la dinámica se modificó con la fragmentación de las grandes haciendas y la expansión de los cultivos - en especial el algodón y la caña de azúcar-, que fueron ganando terreno sobre las inmensas superficies ganaderas. Las pequeñas agroindustrias, los trapiches y las despepitadoras de algodón se multiplicaron en las localidades ribereñas y en sus alrededores. En los últimos años del siglo, algunos molinos, como el de San Cristóbal cerca de Cosamaloapan, se modernizaron y aparecieron otros, como por ejemplo el ingenio de Paraíso Novillero en la margen izquierda del río. Por lo tanto, la demanda de caña de azúcar aumentó y se expandieron los cañaverales en las tierras ribereñas.

Para transportar las cada vez más numerosas mercancías obtenidas de las diversas actividades, barcos de vapor, con gran capacidad de carga, se sumaron al movimiento continuo de embarcaciones a partir de mediados del siglo XIX. Otros barcos provenientes de Europa entraban directamente a Tlacotalpan, declarado puerto de altura en 1820, lo que favoreció el auge de la actividad comercial y significó el apogeo de la ciudad, considerada como "puerta al exterior" de la cuenca (García, 2001: 36-37). Los cuadros de los artistas tlacotalpeños del siglo XIX e inicios del XX, en especial los de Salvador Ferrando y Julio Montalvo, captaron este agitado vaivén incesante (ver imagen 1). La representación del río como vector de numerosas actividades y siempre en un primer plano nos habla de la importancia que tenía en la percepción de los artistas y sin duda de gran parte de la población en aquella época.

La llegada del ferrocarril fue otro aspecto de la modernización de los medios de transporte durante el porfiriato. La vía que afectó a la cuenca — construida menos de 40 años después de la inauguración de la primera vía México-Veracruz en 1864- unía Córdoba con el Istmo de Tehuantepec - Santa Lucrecia- y entroncaba un ramal secundario hacia Veracruz a la altura de Tierra Blanca. Esta vía, inaugurada en 1903, fue construida al oeste y al sur del río, de manera que rodeaba la vasta zona de lagunas situada entre Alvarado y Cosamaloapan (ver mapa 1). A su orilla se fundaron nuevas localidades y se expandieron otras, como por ejemplo el rancho El Hule, rebautizado Papaloapan, el cual estaba situado en el punto de encuentro del río con la vía. El campamento de los obreros que construyeron el puente ferrocarrilero se consolidó formando una pequeña localidad que estaba organizada alrededor de su estación y de la vía. Su papel fue estratégico en la cuenca ya que llegaban allí numerosas lanchas desde los pueblos situados aguas arriba y abajo; las mercancías y pasajeros que desembarcaban tenían que transitar los 500 metros que separaban la orilla del río de la estación y embarcaban posteriormente en los vagones del tren o viceversa. Una década después, otras localidades - como Nopaltepec o Estación Tuxtillase formaron a lo largo de una vía secundaria que enlazó la localidad de Tres Valles, situada en el ramo troncal, con Cosamaloapan, cuya actividad azucarera creciente requirió el nuevo medio de transporte. Finalmente, en 1929, otro tramo secundario fue construido hasta Tuxtepec dando origen a la pequeña población de Pueblo Nuevo, a la orilla de la vía (ver mapa 1).

A pesar de la importancia que adquirió el tren por su gran capacidad de carga y para alcanzar más rápidamente destinos lejanos, como Córdoba y México, el río siguió conservando un papel de comunicación fuerte ya que era fundamental para enlazar los pueblos ribereños con las estaciones. Sin embargo, las localidades situadas totalmente fuera de su área de influencia, como Tlacotalpan, entraron en decadencia al privilegiarse el uso de las nuevas rutas de acero para alcanzar el puerto de Veracruz y el altiplano, vía Córdoba.

Por otra parte, el tren, que permitió el transporte masivo de productos, fue un incentivo para la expansión de los cultivos comerciales como el plátano, la piña y la caña de azúcar (Vargas, 2005: 226). Con la llegada de compañías estadounidenses de exportación, los platanares progresaron en las tierras fértiles del sur de la cuenca, mientras que la caña de azúcar se expandió desde la costa del Golfo hasta el sur de Cosamaloapan. 
Los paisajes, marcados hasta entonces solamente por una actividad ganadera extensiva, conocieron una fuerte antropización.

\section{Las infraestructuras de la Comisión del Papaloapan}

Tras los cambios ocasionados por el paso del ferrocarril, las obras de la Comisión del Papaloapan, conformada en 1947 después de una inundación que devastó Tuxtepec y causó daños en toda la cuenca baja (1944), marcaron una nueva etapa de transformación. Primero se hicieron nuevas infraestructuras para limitar las inundaciones, como la presa Temazcal construida sobre el río Tonto e inaugurada en 1955, muros de protección en las márgenes del río y cortes de los meandros para disminuir el curso de la corriente y aumentar la rapidez del caudal. Se construyeron también carreteras, como el eje poniente-oriente que comunicaba La Tinaja con el Istmo de Tehuantepec y el tramo norte-sur en la margen izquierda que enlazaba Buenavista en la Costa con Ciudad Alemán y luego con Tuxtepec, pasando por Tlacotalpan y Cosamaloapan (ver mapa 1). Otro camino se construyó en la margen derecha entre Pueblo Nuevo y Cosamaloapan, encima del bordo de protección por donde pasaba el antiguo camino real.

Con estas nuevas vías de comunicación, la dinámica de transporte se modificó profundamente. Tanto el transporte fluvial como el ferroviario se vieron afectados. Ya en 1958, un reporte de evaluación de la Comisión del Papaloapan menciona: "un porcentaje muy alto de las mercancías se mueve por carretera, dejando a los ferrocarriles cada vez menos volumen de carga en términos relativos" (Secretaría de Recursos Hidráulicos, 1958: 139). Casi todas las embarcaciones desaparecieron del río, de tal modo que solamente se mantuvieron los chalanes para el transporte de la caña hacia los ingenios - hasta los años ochentay las pangas y lanchas de pasajeros, que permiten atravesar el río en algunos puntos estratégicos. Las tentativas paralelas de la Comisión por reactivar el tráfico fluvial, por ejemplo mediante el dragado del río, fueron abortadas y cayeron en el olvido. En las décadas siguientes, la inauguración de la autopista entre Veracruz y Coatzacoalcos y la pavimentación del camino de la margen derecha (1989) reforzaron la importancia del transporte terrestre. Otra presa, Cerro de Oro, construida sobre el río Santo Domingo aguas arriba de Tuxtepec e inaugurada en 1988, permitió tener aún mayor control sobre las inundaciones.

Con las nuevas vías, la región de la cuenca resultó mucho más comunicada, lo que consolidó la impronta de los cultivos comerciales e impulsó el desarrollo demográfico y las actividades agroindustriales. Las localidades de Cosamaloapan y Carlos A. Carrillo crecieron alrededor de sus dos ingenios, San Gabriel y San Cristóbal, y en Tuxtepec se fundó una papelera en 1954, un ingenio en 1969 -Adolfo López Mateos-y la cervecera Modelo en 1984. La región conoció también un crecimiento demográfico importante a partir de mediados del siglo XX, especialmente notable en el caso de Tuxtepec, ciudad que multiplicó su población por 20 en 70 años (1940-2010) (ver gráfico 1). Dos efectos colaterales fueron la expansión urbana, con el avance de las construcciones en detrimento de las tierras cultivadas, y la contaminación del río, a la cual contribuyó también fuertemente la presencia de las industrias. Como consecuencia, la actividad pesquera se redujo considerablemente en toda la cuenca, así como actividades secundarias tales como la caza o la recolección, que sufrieron también los efectos de la contaminación de las aguas.

Las principales funciones que había desempeñado el río durante la época colonial y la decimonónica desaparecieron entonces en el transcurso del siglo XX: después de ser sustituido como vía de comunicación en los años cincuenta, el río vio reducirse su papel de proveedor de alimentos drásticamente en los años siguientes. En cambio, permanecieron tradiciones festivas y religiosas que nos hablan de la importancia del río como elemento identitario en los siglos pasados: el paso de los toros por el río durante las fiestas titulares; los bailes que se organizan a la orilla; las peregrinaciones religiosas como el paseo del Cristo negro que se lleva por tierra a Papaloapan y se regresa por río a Otatitlán; y las procesiones de la virgen de la Candelaria en Tlacotalpan seguida por todo tipo de embarcaciones, y de la virgen 
de Pentecostés en Amatitlán. Estas tradiciones marcan un fuerte arraigo al río todavía en la actualidad.

\section{La percepción del río por sus habitantes}

Para determinar la relación existente entre la disminución de las actividades funcionales del río y la percepción que tienen de él los habitantes ribereños, seleccionamos cuatro pueblos para aplicar entrevistas. Pretendimos representar con ellos la variedad de las condiciones naturales ya que las localidades están situadas en distintos puntos del río y tienen características específicas así como relaciones particulares con él. En Tlacotalpan y Amatitlán, las dos localidades de la margen izquierda situadas más al norte, las plazas centrales se hallan muy cerca de la ribera y las calles principales se organizan longitudinalmente a ella. Justo enfrente de Tlacotalpan se encuentra la confluencia del río San Juan con el Papaloapan. Más al sur, en la margen derecha, Chacaltianguis tiene su plaza también a la orilla de la corriente y enfrente del pueblo se extiende la pequeña isla de Chacalapa, conocida por los habitantes como "la isleta", situada entre dos brazos del río. En cuanto a Otatitlán, su centro está más alejado del río - 700 metros - y se extiende en parte a lo largo de la corriente y en parte en la ribera del río muerto, resultado del corte del meandro que se realizó en 1949. Al estudiar estos cuatro pueblos en paralelo, nos interesaba saber si a sus características físicas diversas corresponderían percepciones diferenciadas.

\section{El río, elemento identificador pero deteriorado}

En todas las localidades la mayoría de los habitantes considera el río como un elemento esencial de los paisajes. Por ejemplo, en Amatitlán los 17 entrevistados contestaron que el río es importante para la vida del pueblo y 15 lo citan como un elemento representativo y de identidad del pueblo y del paisaje. Estos resultados son bastante homogéneos en todas las localidades. Son los hombres ancianos y adultos quienes manifiestan más entusiasmo y añoranza al evocar la convivencia fuerte que tuvieron con el río en sus años mozos; allí iban a jugar después de la escuela, aprendieron a nadary pescar, atravesaban el río nadando o en bote, o cargaban agua para venderla enlatada en las calles.

Para explicar por qué el río es importante aún hoy, la mayoría cita la actividad pesquera y el papel del río como proveedor de alimentos - 38 de 63 entrevistados-, pero también su importante papel en el abastecimiento de agua para uso doméstico, en las actividades recreativas y festivas, en la fertilización de los campos y de la vegetación, o en el enlace de una ribera con otra mediante el paso de lanchas y pangas. ${ }^{4}$ Otros informantes se refirieron de manera más general al río como fuente de vida: "El río es parte de nosotros y somos parte del río. El río es padre y madre, es fuente de vida" (Julián, Otatitlán). "Es muy importante el río para la vida del pueblo. Allí está la salud, lo necesitamos para vivir" (Pablo, Amatitlán). Algunos habitantes se refieren también a la actividad turística, útil para la economía, y a aspectos estéticos del río como su belleza o lo agradable que resulta vivir a su orilla con la brisa que sopla en tiempos de calor.

Es interesante comprobar que la pesca se menciona de manera recurrente, aunque observamos otra realidad. Efectivamente, hoy en día el número de pescadores ha disminuido como consecuencia de la contaminación de las aguas y el azolve del río y de la barra de Alvarado; los peces de mar ya no entran a desovar en agua dulce y muchas especies, como la lisa y el bobo, han desaparecido. Por lo tanto, la pesca se da ahora de manera preferente en los afluentes del río, en los arroyos y también en los brazos muertos de los meandros y en las lagunas de los alrededores, menos contaminados que el río principal. En Otatitlán, por ejemplo, la asociación acuícola Río Viejo trabaja en el brazo muerto, a salvo de los desechos producidos por las fábricas cercanas de Tuxtepec. Solamente los pescadores ocasionales, que no pueden entrar a esta zona reservada, siguen frecuentando el río de corriente. En Chacaltianguis la pesca se practica sobre todo en el río Obispo, mientras que en Amatitlán se realiza en el brazo muerto de Zopelican y, en ambos casos, en las lagunas de los alrededores. Sólo en Tlacotalpan, y en menor medida en Amatitlán, ${ }^{5}$ se sigue practicando 
en el río de corriente con más frecuencia, aunque con resultados escasos. Parece que la mención recurrente a la pesca como la principal razón de ser del río no corresponde con la situación actual, sino que es más bien una reminiscencia del pasado.

Si bien son recurrentes las menciones positivas a la ubicación de la localidad cerca del río, la mayoría de los habitantes se refiere también al peligro que representan las inundaciones - 45 de 63-. Antes de 2010, los jóvenes no habían conocido ninguna y era un viejo recuerdo para los ancianos y adultos ya que el agua no había entrado a los pueblos durante más de 40 años como resultado de la construcción de las dos presas. ${ }^{6}$ Pero la crecida de 2010, que tuvo consecuencias importantes en todos los pueblos, y especialmente en Tlacotalpan, evacuado en su totalidad, dejó huellas. A pesar de las obras, del monitoreo del río y de las precauciones tomadas, los habitantes piensan ahora que puede volver a ocurrir y la preocupación es fuerte en temporada de lluvias.

Por otra parte, los habitantes ribereños, independientemente de su edad, género y condición social, son conscientes de las malas condiciones del río: citan la contaminación, el azolve y el desbarranque de las riberas como problemas principales. A la pregunta de cómo podría mejorar el río, se refieren casi siempre al control de la contaminación en su localidad o en las industrias aguas arriba y al dragado del río, que no se ha hecho en décadas y podría reducir el impacto de las inundaciones. Pero, a pesar de conocer la existencia de problemas graves que afectan y deterioran un elemento del paisaje valorado y muy presente, existen pocas iniciativas en defensa del río. La asociación Unidos por el Río Papaloapan, con base en Tuxtepec y que ha organizado varias acciones y programas de concientización, se encuentra bastante aislada. La idea de que son los políticos quienes deberían solucionar el problema y actuar está arraigada. Existieron sin embargo algunas iniciativas aisladas. Por ejemplo, en Amatitlán, en los años noventa, un programa de concientización intentó evitar que la población tirara basura al río, y en Chacaltianguis las autoridades municipales (2011-2013) tienen programada la construcción de una planta de tratamiento de aguas residuales para evitar las descargas en el río, ${ }^{7}$ la cual ya está construida en Otatitlán y se encuentra en espera de inauguración.

\section{Las particularidades de la relación con el río en cada pueblo}

La relación geográfica particular que existe entre cada pueblo y "su" río da lugar a algunas diferencias en las percepciones. Los dos pueblos situados más al norte parecen tener una relación más íntima con el Papaloapan. En Amatitlán, pueblo de tamaño modesto - 1251 habitantes en la cabecera en 2010-, cuya población entera vive a menos de 300 metros del río, las referencias al malecón son recurrentes. Al explicar lo agradable que es vivir tan cerca del río, los habitantes mencionan la vista hermosa que tienen desde el malecón sobre la ribera opuesta, con su vegetación arboleada, y la brisa que corre y refresca los días de calor. Además, como el agua para uso doméstico se extrae directamente del río y algunos pescadores siguen trabajando allí, la corriente de agua continúa teniendo cierta funcionalidad que es reconocida y valorada por los habitantes. La imagen que los niños proyectan en los dibujos de su pueblo refleja también esa cercanía, ya que la mayoría de ellos representa el río ${ }^{9}-12$ de $22-$ (ver imágenes 2 y 3 ).

En Tlacotalpan, localidad de 7600 habitantes y con cierta actividad turística, ${ }^{10}$ las principales actividades - los paseos turísticos en lanchas, la oferta de comida en los locales de la ribera o la pesca- están relacionadas con el río. Además, el Papaloapan sigue presente en la cultura y las artes que permanecen como herencia del siglo XIX, como en los marcos de los pintores Ignacio Canela, Eugenio Pestaña y contemporáneos, en los versos de los decimeros y poetas o en el repertorio del son jarocho. A nivel de su traza urbana, la localidad está estructurada en función del río y para mantener una estrecha relación con él, de lo que dan un claro ejemplo los edificios del palacio municipal con vista al muelle, los callejones que desembocan en el río o la carretera de entrada a la localidad desde Buenavista que bordea la ribera. La relación con el río es constante, es decir, no depende de la época de calor como en otros pueblos - aunque puede ser más intensa-y trasciende 
las generaciones y clases sociales. Todos tienen un acercamiento con el río: los jóvenes que van al callejón El Cabezo para "tirarse un clavado" después de los horarios de escuela, los hombres que acuden a la orilla a disfrutar de la puesta del sol, la anciana que se subió a una lancha para arrojar las cenizas de su hermano a la corriente, los pescadores profesionales u ocasionales, o la maestra que organiza visitas turísticas guiadas, por citar algunos ejemplos concretos. ${ }^{11}$

Chacaltianguis presenta una situación un poco distinta pues la relación con el río se concentra casi exclusivamente en la isleta, citada por casi todos los entrevistados como un elemento esencial del paisaje y de la identidad del pueblo. Lugar de fábrica de cal, de cultivos diversos - mango, plátano o caña-y de pesca de camarón, se volvió una zona de recreación y convivencia importante para las familias del pueblo y para los visitantes en temporada de calor, cuando en la primera década de este siglo se construyó un puente colgante para unirla con el pueblo y se empezó a organizar allí en Semana Santa la presentación de las candidatas a reina para la feria del mango ${ }^{12}$ (ver imagen 4). Debido a esta relación, estrecha e importante en la vida de la población, aunque limitada en el tiempo, cinco de los 18 entrevistados consideran que hay mayor relación entre los habitantes y el río ahora que antes - percepción marginal en los otros pueblosDespués de varios proyectos turísticos abortados, el ayuntamiento intenta actualmente promover allí un proyecto ecoturístico. De manera paradójica, seis entrevistados en esta localidad -más que en los otros pueblos - señalan indiferencia o incluso cierta aversión por el río; se trata en especial de ancianos, la categoría que habitualmente ha tenido más apego y relación con él. A Catalina, 80 años, "le da temor acercarse al río, no va nunca"; Guadalupe, 94 años, contesta que "el río es peligroso; nunca he ido porque mi familia no acostumbraba ir" - a pesar de vivir a dos cuadrasJesús, 84 años, contesta que "el río ni aporta ni afecta", "nunca me ha gustado, ahora menos con las sustancias que le echan". Y sólo diez de 23 dibujos de los niños lo representan. ${ }^{13}$ La contaminación y las inundaciones que provocaron mucha destrucción tanto en 1944 como en 1969 y afectaron parte del pueblo en 2010 - son citadas de manera recurrente para explicar este alejamiento. Por otra parte, la importancia que tienen las lagunas cercanas y el río Obispo para nadar y pescar puede ser otro elemento de explicación.

En el caso de Otatitlán existen, como en las otras localidades, un acercamiento a las playas en tiempo de calor y una actividad pesquera residual - ya mencionada-, a pesar de la fuerte contaminación citada con insistencia, ya que el pueblo se halla a sólo a 25 kilómetros de Tuxtepec. Sin embargo, parece existir también aquí cierta distancia con el río; distancia geográfica en primer lugar, ya que 700 metros separan al malecón de la plaza central, por lo cual la convivencia con el río es obviamente menor que en los otros tres pueblos. Por otra parte, la referencia espacial que marca la identidad citada de manera recurrente es el santuario, donde se venera la imagen del Cristo negro, lo cual explica que el río pase a un segundo plano. Además, varios de los habitantes mencionan la incomunicación del pueblo y evocan la necesidad de construir un puente o de restablecer la panga - que dejó de funcionar al inicio de los años setenta-, mientras que el lugar del río citado más frecuentemente es el paso de la lancha, que utilizan los habitantes para llegar a la carretera federal que enlaza Cosamaloapan con Tuxtepec. El deseo de ir más allá del río y la necesidad de apertura parecen ser más importantes en Otatitlán que en los otros pueblos. Esta distancia se refleja también en los dibujos de los niños ya que sólo siete de 21 representan el río. ${ }^{14}$

\section{Conclusión}

Aunque los habitantes de los pueblos de la ribera del Papaloapan manifiestan en general una fuerte sensibilidad a los paisajes fluviales, existe una apropiación espacial diferenciada en los pueblos estudiados. Los pueblos del norte de la cuenca parecen seguir vinculados más fuertemente con su río que los dos pueblos situados más al sur, lo que se refleja tanto en las entrevistas como en los dibujos de los niños por lo menos en el caso de Otatitlán, Chacaltianguis y Amatitlán-. Tales resultados pueden deberse a la 
contaminación industrial que afecta más fuertemente a los pueblos más cercanos a la localidad industrial de Tuxtepec y a otros factores históricos o recientes, como la reestructuración de la traza urbana en Otatitlán, consecuencia del corte del meandro o la concentración del interés por el río en un solo lugar y en un periodo determinado del año en el caso de Chacaltianguis.

El vínculo afectivo fuerte que la mayoría de los habitantes mantiene con el río a pesar de estas diferencias locales se puede explicar por la percepción que tienen del río como un elemento patrimonial, pilar de la historia local y vector de una identidad común. Impregnados por la historia, los habitantes siguen atribuyendo al río ciertas funciones, de vía de comunicación y proveedor de alimentos, a pesar de que hayan decaído o desaparecido. Los numerosos y diversificados argumentos para justificar la importancia del río, el discurso nostálgico y poético utilizado para referirse a él o el hecho de que siga siendo fuente de inspiración para los poetas y los pintores, evocan un elemento paisajístico e identitario que sigue vivo para los habitantes a pesar de su deterioro.

Para que no se vuelva un marco vacío y pueda seguir siendo vector de actividades, tales como los paseos turísticos en lancha o la pesca, es necesario actuar para su conservación mediante el control de la contaminación y del azolve, que limitan o imposibilitan las actividades mencionadas. La mayoría de los habitantes ribereños son conscientes de los problemas que enfrenta su río; sin embargo, en cada pueblo se piensa a nivel local sin considerar que los problemas son semejantes a todo lo largo de la corriente. Paradójicamente, al mismo tiempo que el río permanece muy presente, parece que el sentimiento de pertenencia a una misma cuenca ha disminuido, interferido por los nuevos medios de comunicación y la apertura a las regiones vecinas. Sin embargo, la cuenca baja presenta una fuerte homogeneidad cultural por su historia común, sus paisajes que siguen el eje conformado por el río, y por otros rasgos que la determinan: los cultivos - caña, plátano o árboles frutales-; la arquitectura con casas de tejas y corredores que permanece sobre todo en
Tlacotalpan, Chacaltianguis y Otatitlán; la música, con el son jarocho rescatado ya en varios pueblos; las fiestas, con el embalse de los toros, el desfile de las mojigangas, las ramas o las bohemias; la artesanía - rejillado, bordado, mallas-; o la comida entre otros elementos. Para ejercer presión sobre las fábricas industriales de Cosamaloapan y Tuxtepec, con el fin de que se prohíban los desagües, y para solicitar al gobierno estatal el dragado del río, sería necesaria una reorganización y mayor unidad a nivel de toda la cuenca baja siguiendo el hilo conductor que constituye la corriente del río Papaloapan.

\section{Notas}

${ }^{1}$ Los paisajes fluviales son los que están relacionados con un río y se encuentran en un valle fluvial. El eje central de estos paisajes es la corriente de agua; los paisajes estudiados se pueden extender en franjas más o menos anchas a lo largo de ésta según los intereses del investigador. Son paisajes móviles, ya que se suceden a la orilla del curso del río, con usos de suelo diversos - urbano, industrial o rural-y se transforman a lo largo del año según la variabilidad del caudal, las inundaciones, etcétera (Valette, 2004).

${ }^{2}$ Tres localidades importantes están en la confluencia del Papaloapan con otros ríos: Tlacotalpan (río San Juan), Cosamaloapan (río Obispo) y Tuxtepec (río Tonto).

${ }^{3}$ Esto contrasta con la percepción de catástrofe natural que predomina actualmente.

${ }^{4}$ Es interesante señalar que los habitantes no se refieren al río como a un obstáculo que dificulta la comunicación en la región. Solamente en Otatitlán se mencionó la incomunicación del pueblo.

${ }^{5}$ La contaminación constante que proviene de las fábricas de Tuxtepec se resiente menos a esta altura del río que en las localidades situadas más al sur, por la distancia y el hecho de diluirse con el agua de los afluentes. La contaminación por los ingenios de Cosamaloapan y Carlos A. Carrillo es temporal - meses de zafra- y parte de las descargas se hace en la laguna de Acula.

${ }^{6}$ La penúltima inundación importante fue en 1969, cuando la presa Cerro de Oro aún no existía. 
${ }^{7}$ En los distintos pueblos existen fosas sépticas, pero las casas de la orilla desaguan directamente sus aguas residuales al río, incluso en Tuxtepec, ciudad de 100000 habitantes.

${ }^{8}$ Es una población rural, según la clasificación del INEGI.

${ }^{9}$ Dibujos realizados por 22 alumnos de cuarto y quinto de la Escuela Primaria Estatal José María Pino Suárez (clave 30EPR0202Ml).

${ }^{10}$ Localidad con el título de Patrimonio de la Humanidad de la UNESCO desde 1998. El turismo es masivo durante los festejos de la Candelaria, pero la ciudad conoce también cierta afluencia los fines de semana y durante el verano. Se trata de un turismo nacional e internacional — tours desde Veracruz, por ejemplo-.

${ }^{11}$ Es interesante mencionar que son pocos los niños que representan el río -4 de 12 -, seguramente porque hay otros elementos relacionados con el turismo y la cultura - por ejemplo, la pareja de bailarines jarochos del muelle-,que les parecen más emblemáticos. Dibujos realizados el 16 de mayo de 2012 en la Escuela Primaria Estatal Miguel Z. Cházaro, Tlacotalpan (clave 30EPR2430U).

${ }^{12}$ La feria del mango inició en 1954 para celebrar la cosecha de este cultivo, en pleno auge en aquella época. La coronación de la reina se hace en mayo en la plaza principal y es la fiesta más importante junto con la fiesta titular del Niño Jesús en enero.

${ }^{13}$ Alumnos de tercer grado de la Escuela Primaria Estatal Vicente Guerrero, Chacaltianguis (clave 30EPR0730D).

${ }^{14}$ Dibujos realizados el 15 de marzo de 2013 por los alumnos de segundo y cuarto de primaria de la Escuela Primaria Estatal Benito Juárez, Otatitlán (clave 30EPR1559R).

\section{Bibliografía}

Aguirre Beltrán, Gonzalo (2008), Pobladores del Papaloapan: biografía de una hoya, México: CIESAS.

Córdoba Olivares, Francisco Rubén (1998), “Cristo, vírgenes y santos en el bajo Papaloapan”, en Gilberto Silva-López, Guadalupe Vargas Montero y José Velasco Toro (coords.), De padre río y madre mar. Reflejos de la cuenca baja del Papaloapan, Veracruz, Xalapa: Gobierno del Estado de Veracruz, t. 1, pp. 165-191.
Di Méo, Guy (2002), "L'identité: une médiation essentielle du rapport espace/société”, en Géocarrefour, vol. 77, núm. 2, 〈http://www.persee.fr/web/revues/ home/prescript/article/geoca_1627-4873_2002_ num_77_2_1569: [6 de febrero de 2013].

Di Méo Guy, Claire Sauvaitre y Fabrice Soufflet (2004) “Les paysages de l'identité (le cas du Piémont béarnais, à l'est de Pau)”, en Géocarrefour, vol. 79, núm. 2, 〈http://geocarrefour.revues.org/639〉 [10 de febrero de 2013].

García de León, Antonio (2011), Tierra adentro, mar en fuera. El puerto de Veracruz y su litoral a Sotavento, 15191821, México/Xalapa: Fondo de Cultura Económica/ Gobierno del Estado de Veracruz/Universidad Veracruzana.

García Díaz, Bernardo (2001), Tlacotalpan, patrimonio de la humanidad, Xalapa: Gobierno del Estado de Veracruz.

INEGI, Marco geoestadístico nacional, Archivo Histórico de Localidades, htttp:/www.inegi.org.mx/geo/contenidos/ geoestadistica/archivohistloc.aspx> [12 de abril de 2013].

Montero García, Luis A., Israel Sandré Osorio y José Velasco Toro (coords.) (2011), Mariposas en el agua. Historia y simbolismo en el Papaloapan, Veracruz: Universidad Veracruzana.

Montero García, Luis A. y José Velasco Toro (coords.) (2005), Economía y espacio en el Papaloapan veracruzano Siglos XVII-XX, Xalapa: Gobierno del Estado de Veracruz.

Nogué, Joan (2006), "La producción social y cultural del paisaje”, en Rafael Mata y Álex Tarroja (coords.), El paisaje y la gestión del territorio: criterios paisajísticos en la ordenación del territorio y el urbanismo, Barcelona: Diputació Barcelona/Xarxa de municipis, pp. 135-143. Pizarro, Ana (2009), Amazonia: el río tiene voces, Santiago de Chile: Fondo de Cultura Económica.

Secretaría de Recursos Hidráulicos, Comisión del Papaloapan (1958), Economía del Papaloapan. Evaluación de las inversiones y sus efectos, México: la Secretaría.

Silva-López, Gilberto, Guadalupe Vargas Montero y José Velasco Toro (coords.) (1998), De padre río y madre mar. Reflejos de la cuenca baja del Papaloapan, Veracruz, Xalapa: Gobierno del Estado de Veracruz, t. 1. 
Silvestri, Graciela (2012), El color del río. Historia cultural del paisaje del Riachuelo, Buenos Aires: Universidad Nacional de Quilmes.

Valette, Philippe, Jean-Marc Antoine, Bertrand Desailly y François Gazelle (2004), "Les temps de la production des paysages fluviaux urbains, quelques exemples dans le Sud-Ouest de la France", en Colloque Dela connaissance des paysages à l'action paysagère, Bordeaux, Francia. ‘http:// www.symposcience.org/exl-doc/colloque/ART00001252.pdf> [24 de febrero de 2013].

Vargas Montero, Guadalupe (2005), "Plantación piñera en el ámbito del Papaloapan”, en Luis A. Montero García y José Velasco Toro (coords.), Economía yespacio en el Papaloapan veracruzano Siglos XVII-XX, Xalapa: Gobierno del Estado de Veracruz, pp. 21l-257.
Velasco Toro, José (2004), "Espacio y cultura ganadera colonial en la región del bajo Papaloapan, Veracruz", en José Velasco Toro y David Skerritt Gardner (coords.), De las marismas del Guadalquivir a la costa de Veracruz: cinco perspectivas sobre cultura ganadera, Veracruz: Instituto Veracruzano de la Cultura, pp. 55-85.

Velasco Toro, José y Gustavo Ramos Pérez (2011), "Agua: símbolo de vida y muerte en el Bajo Papaloapan", en Luis A. Montero G., Israel Sandré Osorio y José Velasco Toro (coords.), Mariposas en el agua. Historia y simbolismo en el Papaloapan, Veracruz: Universidad Veracruzana, pp. 21-46.

Velasco Toro, José (2003), Tierra y conflicto social en los pueblos del Papaloapan veracruzano (1521-1917), Veracruz: Universidad Veracruzana. 
Mapa 1. La cuenca baja del Papaloapan

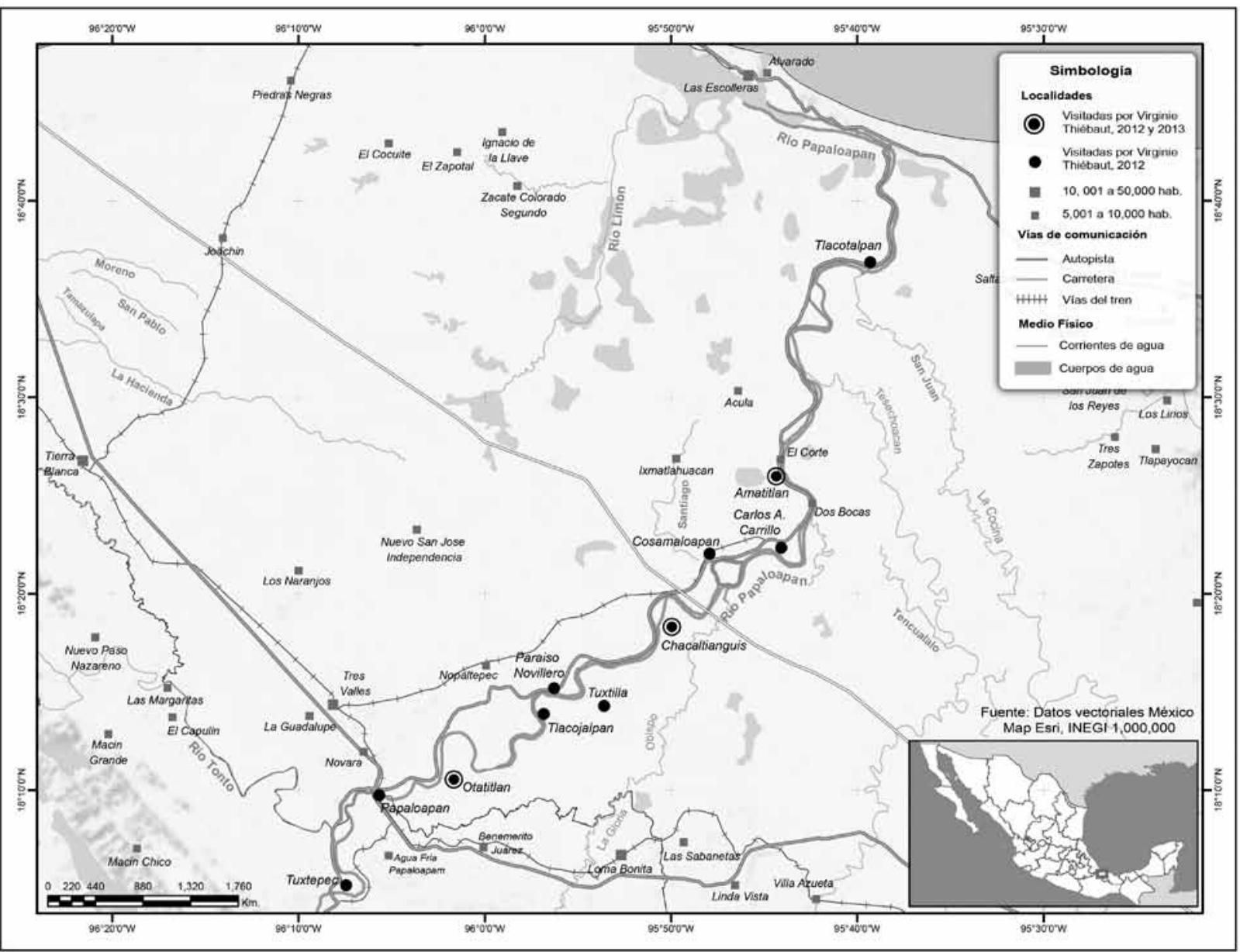


Mapa 2. Parte occidental del Istmo, 1793

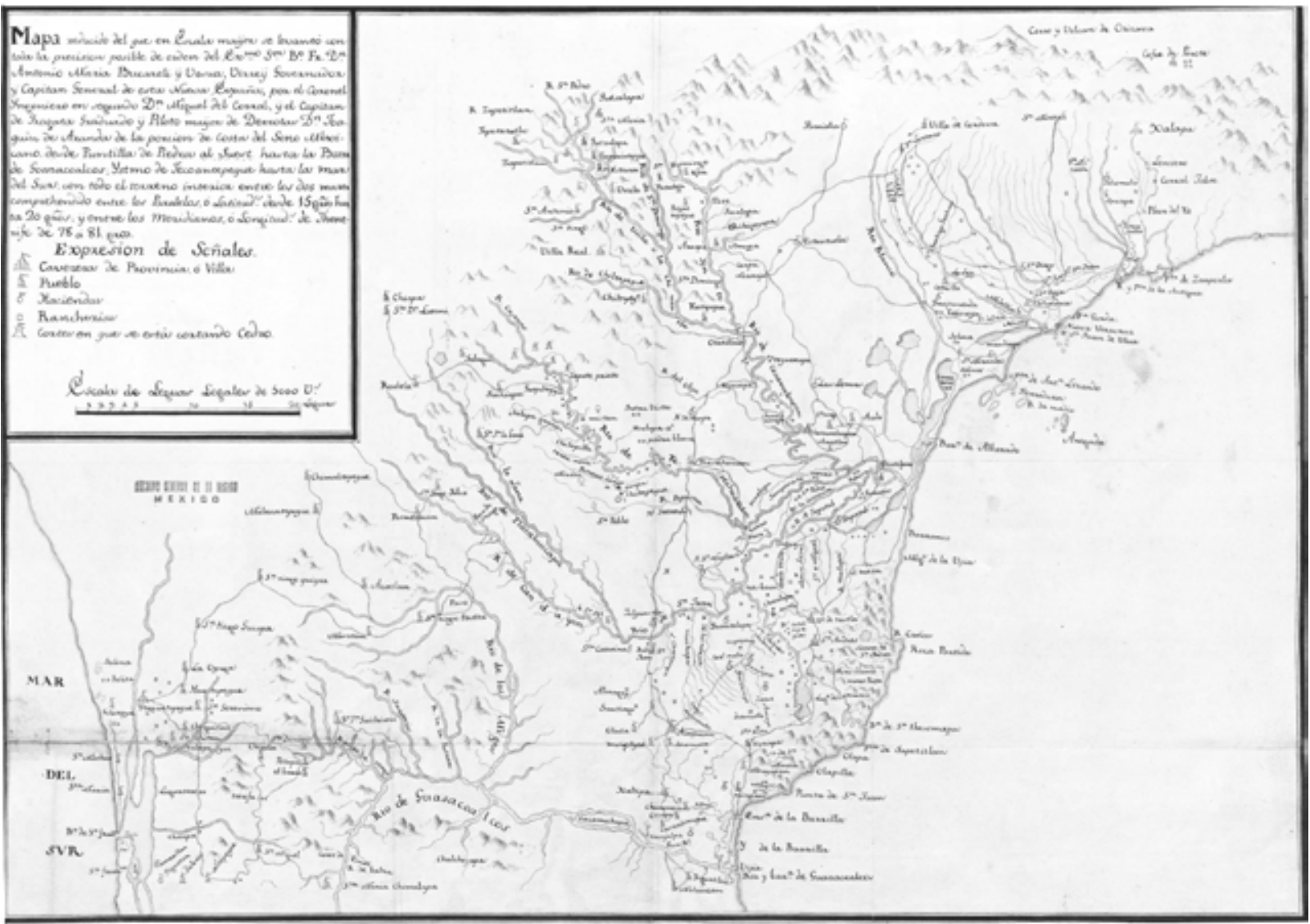

Fuente: Archivo General de la Nación. Número de pieza: 0373. Clasificación: 977/0361. Historia, vol.359, exp. 4, f. 85.

Se aprecia cómo la red acuática de transporte entre "los dos mares", complementada por los caminos de arriero, unía la sierra de Oaxaca, la costa del Golfo y el Altiplano. 


\section{Imagen 1. Panorámica de Tlacotalpan}

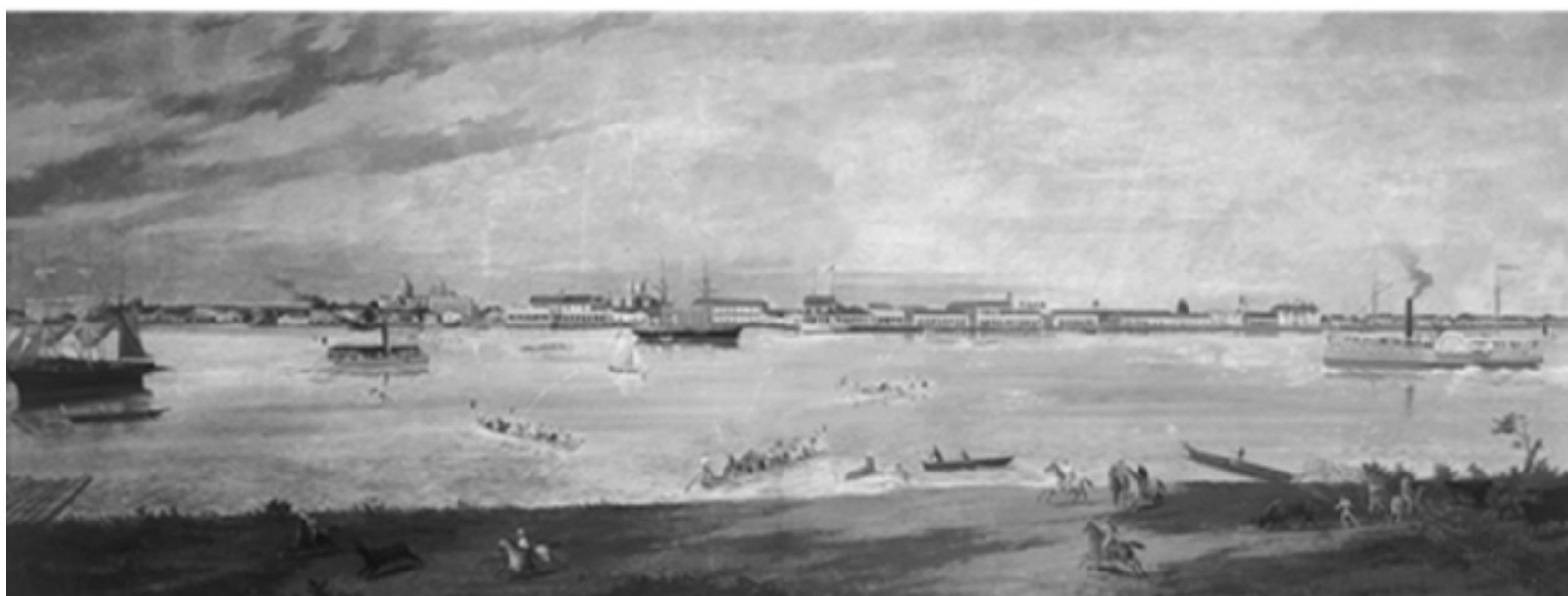

Fuente: Salvador Ferrando, óleo sobre tela, ca 1890. Tomado de García (2001).

\section{Imagen 2. El malecón de Amatitlán desde el cual se aprecia la ribera arbolada opuesta}

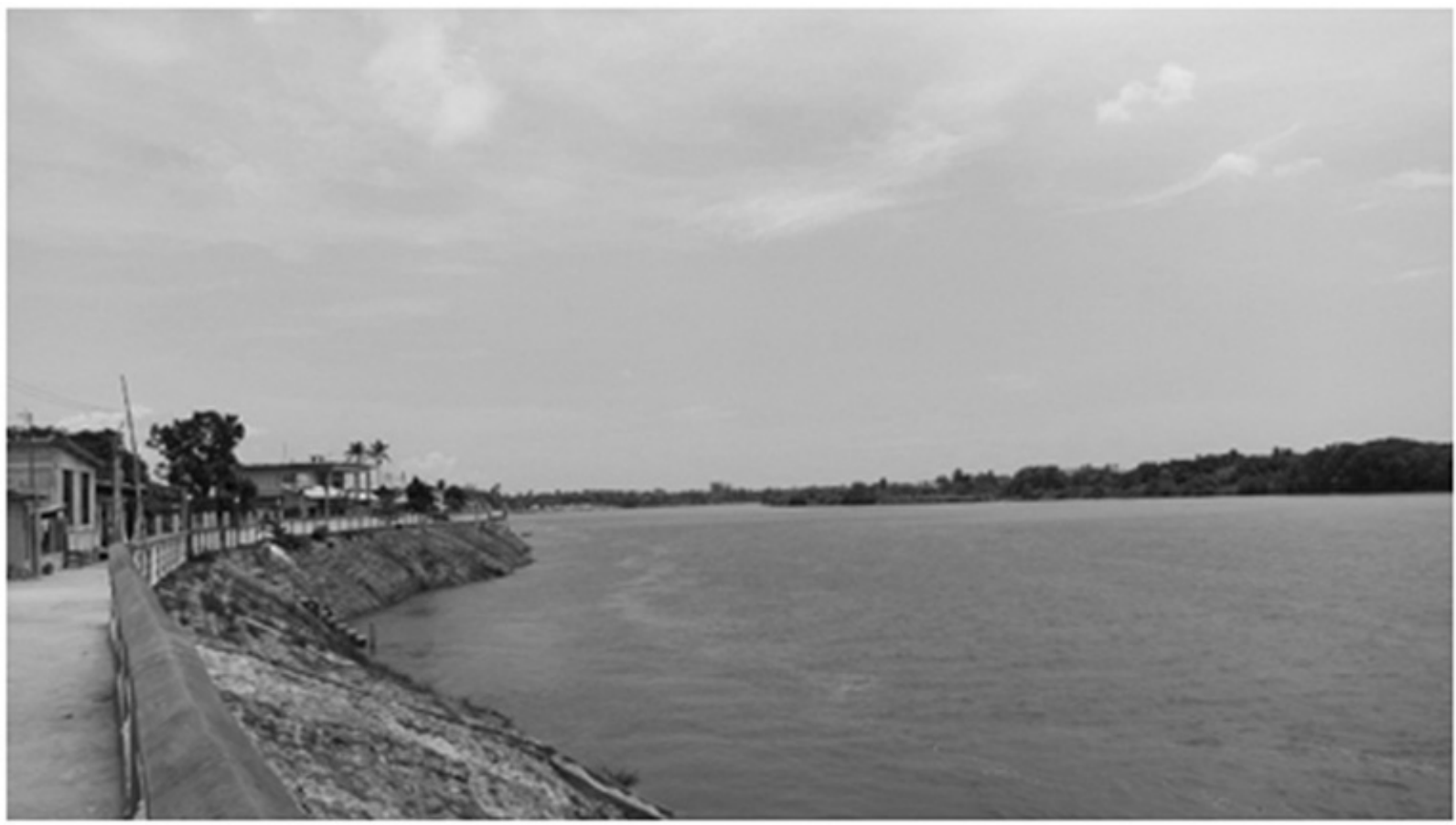

Fuente: Virginie Thiébaut, mayo de 2012. 


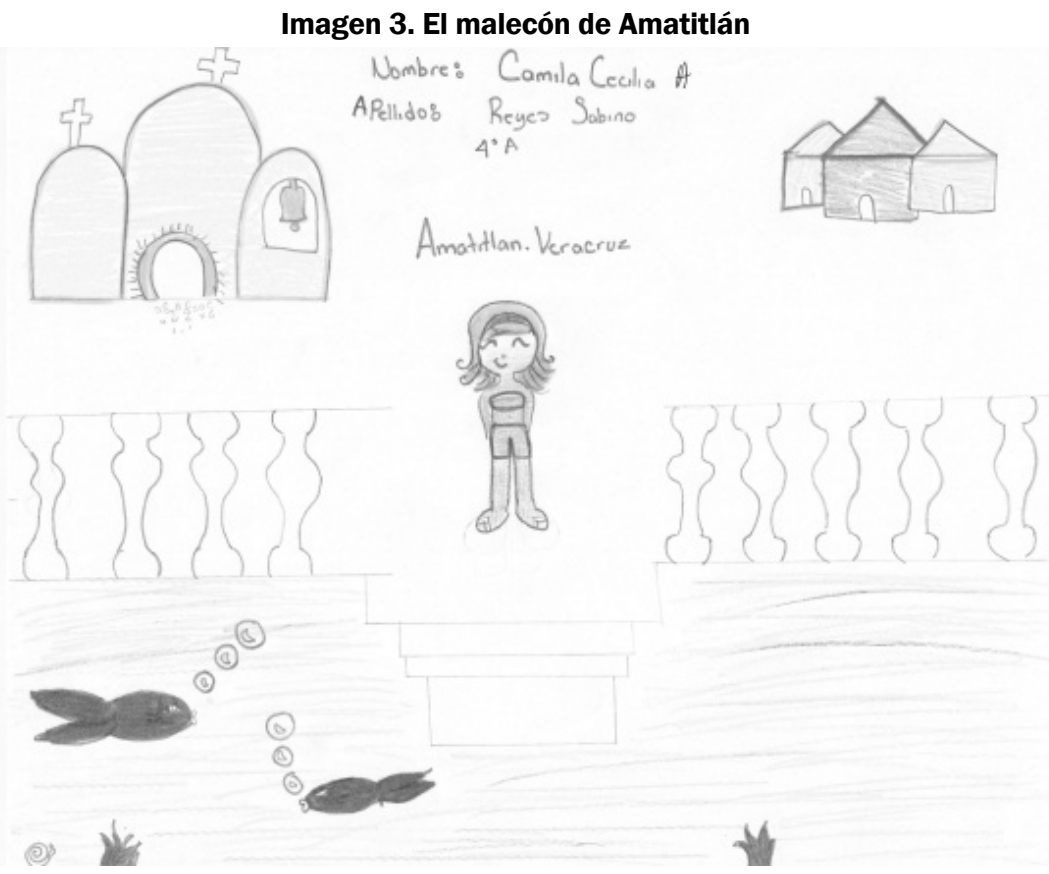

Fuente: Camila Cecilia, 10 años.

Imagen 4. La isla de Chacalapa, muy visitada en Semana Santa

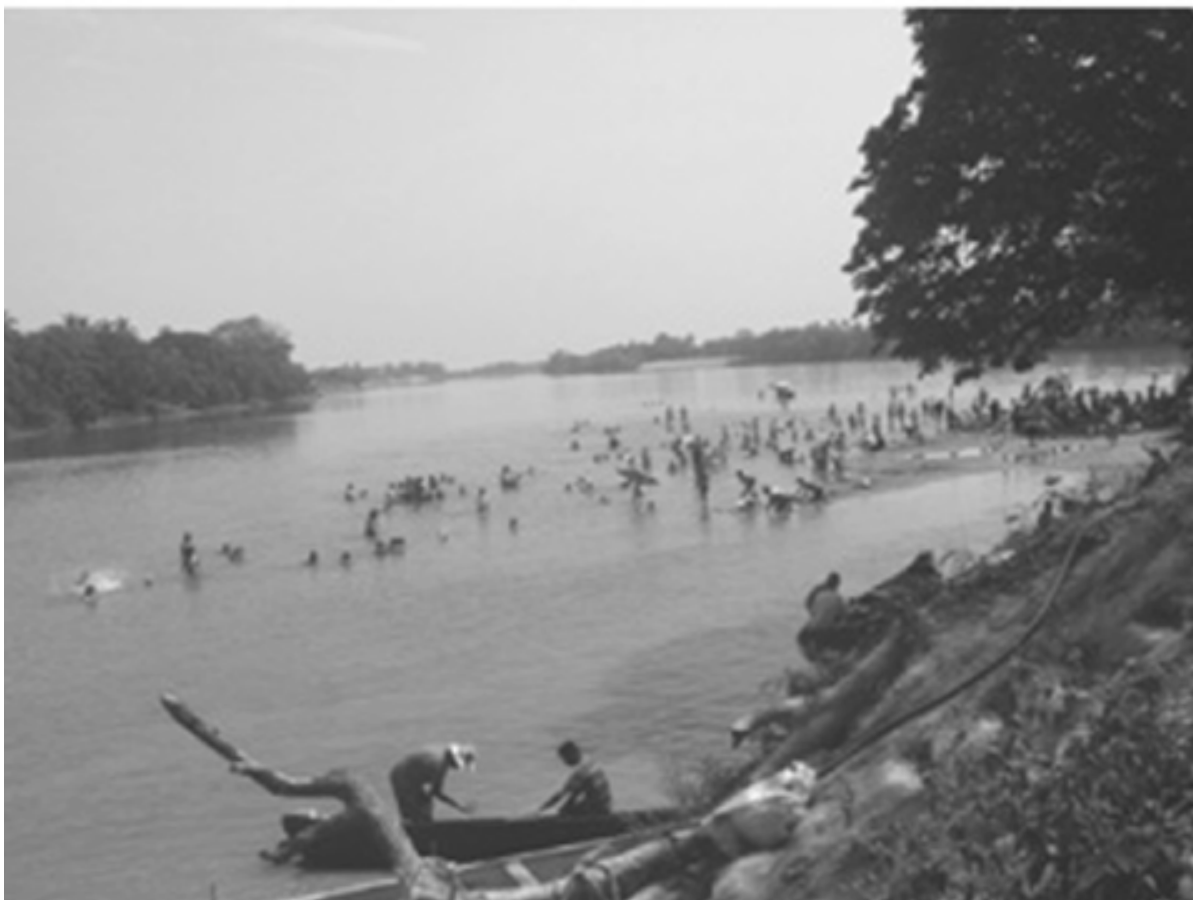

Fuente: Noé Miranda Hernández, abril de 2012. 
Tabla 1. Entrevistas efectuadas en marzo y abril de 2013

\begin{tabular}{|c|c|c|c|c|c|}
\hline & Tlacotalpan & Amatitlán & Chacaltianguis & Otatitlán & Total \\
\hline entrevistados & 10 & 17 & 18 & 18 & 63 \\
\hline hombres & 5 & 9 & 8 & 8 & 30 \\
\hline mujeres & 5 & 8 & 10 & 10 & 33 \\
\hline de 16 a 35 años & 2 & 5 & 5 & 5 & 17 \\
\hline de 36 a 55 & 4 & 4 & 4 & 4 & 16 \\
\hline de 56 a 75 & 2 & 6 & 5 & 4 & 17 \\
\hline 76 años y más & 2 & 2 & 4 & 5 & 13 \\
\hline
\end{tabular}

Fuente: elaboración propia. Las clases sociales no han sido indicadas, pero cabe señalar que fueron entrevistadas personas con perfiles muy distintos, como pescadores, campesinos, profesionistas, comerciantes, estudiantes y prestadores de servicios.

Tabla 2. Crecimiento demográfico de cuatro localidades de la cuenca (1940-2010)

Sobre identidad y lugar

1 ¿Con qué lugar, espacio, región se siente identificado? ¿De qué lugar se siente más cercano? ¿A qué lugar tiene el sentimiento de pertenecer? ¿Cuál es "su tierra", "su terruño"?

2 ¿Qué evoca para usted este lugar? ¿Qué es lo más representativo? ¿Qué imágenes le vienen a la mente cuando está lejos de este lugar y piensa en él?

3 En este espacio, ¿existen uno o varios paisajes que aprecia especialmente? ¿Los puede describir?

4 ¿Qué no le gustaría que desapareciera dentro de estos paisajes?

5 ¿Qué lugares les enseñaría a amigos de fuera que le hacen una visita?

6 ¿Piensa que hay una evolución, unos cambios en estos lugares o que no cambian? Citar algunos ejemplos de cambios significativos.

7 ¿Hay medidas o realizaciones que se hicieron y que le parecen bien para la conservación de estos paisajes o para su mayor valoración?

Sobre el río

1 ¿Qué acercamiento tenía con el río antes?

2 ¿Qué acercamiento tiene con el río ahora?

3 ¿El río le parece importante para la vida del pueblo? ¿En su vida personal?

4 ¿Vivir cerca de un río le parece bueno o malo? ¿Representa un peligro? ¿Una ventaja? Justificar.

5 ¿Qué experiencia tuvo de las inundaciones pasadas?

6 ¿Le parece que el río ha cambiado o no? ¿Y las riberas, el entorno del río? ¿En qué aspecto?

7 ¿Qué se podría hacer para mejorar el río?

8 ¿Le parece que hay más relación de la población con el río ahora o que había más antes? Justificar.

Fuente: INEGI, Archivo Histórico de Localidades. 
Gráfico 1. Crecimiento demográfico de cuatro localidades de la cuenca (1940-2010)

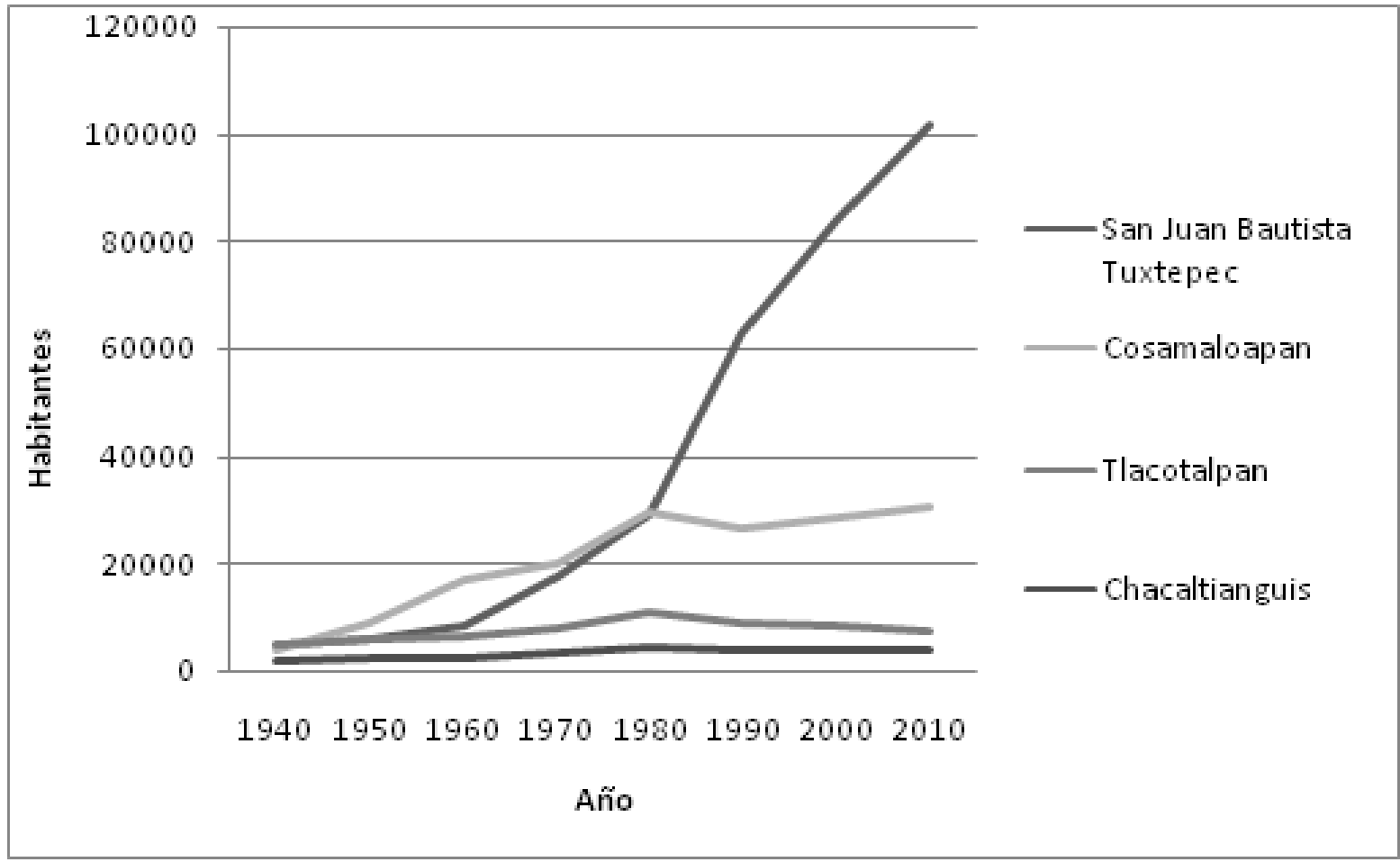

Fuente: INEGI, Archivo Histórico de Localidades. 